\title{
SYMPTOMATIC HAEMOLYTIC ANAEMIA ASSOCIATED WITH OVARIAN TERATOMA IN A CHILD
}

BY

\author{
E. C. AllibONE and D. H. COLlins \\ From the General Infirmary at Leeds and University of Leeds Departments of \\ Paediatrics and Pathology
}

(RECEIVED FOR PUBLICATION MARCH 9, 1951)

Symptomatic haemolytic anaemia has been defined by Singer and Dameshek (1941) as a haemolytic syndrome often indistinguishable by haematological methods from the well-known picture of familial haemolytic jaundice, but showing a definite aetiological relationship to an underlying disease such as neoplasm, leukaemia, or Hodgkin's disease. The diagnosis of symptomatic haemolytic anaemia can only be accepted, as Davis (1944) points out, when there are reasonable grounds for concluding that the anaemic state results mainly, or exclusively, from accelerated red cell destruction, which in turn is conditioned by the development of an underlying morbid process. "In other words," Davis writes, " there must be evidence that the anaemia is of haemolytic origin, and that its onset was preceded by the underlying primary condition." Judged by these criteria, the diagnosis of symptomatic haemolytic anaemia in the case we are about to report cannot be disputed. There was every evidence of accelerated red cell destruction, and the ovarian teratoma must have originated before the anaemia, although its presence was not detected until the child became anaemic. A total remission of the haemolytic syndrome immediately followed the removal of the teratoma, a fact which strongly suggests an aetiological role on the part of the tumour in the causation of the anaemia. Such well-defined examples of symptomatic haemolytic anaemia are rare, and only four instances where the anaemia was associated with an ovarian tumour have hitherto been reported in the literature.

\section{Clinical Features}

A girl, aged 4 years 9 months, was referred to the General Infirmary at Leeds in April, 1950, with anaemia. Three months previously, at a routine visit to a welfare centre, pallor was noticed, for which iron was prescribed. She remained well until eight weeks before attending hospital, when she complained of pains in her limbs and was observed to be jaundiced. Her mother noted that the urine was dark and thick. No change had been noticed in the stools, which were black. After a week she began to improve, and by the end of six weeks she seemed to have recovered. Shortly afterwards, ten days before admission, the jaundice recurred, and this was associated with listlessness and anorexia, but there was no change in the colour of faeces or urine. 
On examination the patient was seen to be a moderately well nourished, fair-haired girl weighing $34 \mathrm{lb}$. She was clearly anaemic and slightly jaundiced. The liver and spleen were not enlarged. A firm rounded mass, the size of a tangerine, was felt just above the pubis, and slightly to the right of the mid-line. It was not tender, and it could be moved slightly from side to side. The tumour was not palpable on rectal examination, and was not altered by repeated enemata and vesical catheterization. The external genitalia were normal. No other relevant findings were noted.

Laboratory investigations, details of which are given below, showed a severe haemolytic anaemia. The pelvis was examined radiologically, and a molar tooth with some adjacent irregular calcified shadows was seen in the position of the tumour. In view of the known association of ovarian teratoma with symptomatic haemolytic anaemia, and of the failure of splenectomy alone in some reported cases, it was decided to observe what effect the initial removal of the ovarian tumour had on the anaemia.

On May 20 a transfusion of $300 \mathrm{ml}$. of cross-matched Group $\mathrm{O}$ whole blood was given slowly. There was no untoward reaction. The blood haemoglobin was thereby raised, but signs of active haemolysis persisted. On May 23 the child received a further transfusion of $1,000 \mathrm{ml}$. of blood.

On May $24 \mathrm{Mr}$. A. J. C. Latchmore operated, and through a right paramedian incision removed a unilocular cystic teratoma (dermoid cyst) of the right ovary $7.5 \mathrm{~cm}$. in diameter. After excision a tiny portion of the ovary remained proximal to the ligature. The left ovary felt normal.

Recovery from the operation was uneventful. On the third day the haemoglobin had fallen to $86 \%$, but had returned to $100 \%$ on the fifth day (Table I). The patient was discharged on June 12, and when last seen four months later was symptom-free and in good health.

TABLE I

ANALYSES OF BLOOD CounTs

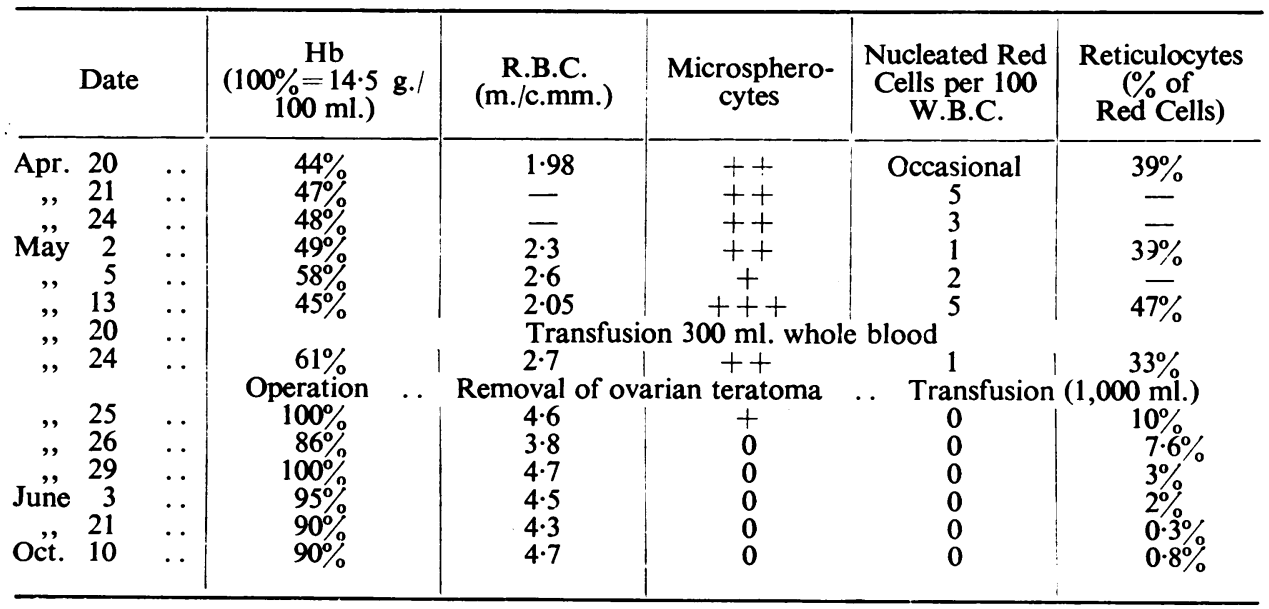

\section{Laboratory Investigations}

Haemoglobin and Red Cells.-Before treatment (Table I) $\mathbf{H b}$ varied from $44 \%$ $(6.38 \mathrm{~g} . / 100 \mathrm{ml}$.) on admission to $58 \%(8.41 \mathrm{~g} . / 100 \mathrm{ml}$.$) , and the red cell count from$ 
1.98 to $2.6 \mathrm{~m}$. $/ \mathrm{c} . \mathrm{mm}$. Both the red cell count and haemoglobin improved slowly after admission, but 10 days before operation there was a relapse.

Red Cell Size.-On May 5 the mean corpuscular volume (MCV) was 92 c. $\mu$, the mean corpuscular haemoglobin (MCH) $32 \gamma \gamma$, and the mean corpuscular haemoglobin concentration (MCHC) 35\%. These estimations, which all gave normal values, were not repeated. The mean corpuscular diameter (MCD) on May 13, before operation, was $7.15 \mu \pm 1.231$, and on June 3, after operation, $7.34 \mu \pm 0.626$. Both mean diameters are within the normal range and do not differ significantly one from another (difference between means $=0.19 \mu$ : standard error of difference between means $0.138 \mu$ ). The large variation in red cell size, existing before operation, indicated by the S.D. of $1.231 \mu$, was due to the presence of both microspherocytes and macroreticulocytes, and this variation was significantly reduced after operation to an S.D. of $0.626 \mu$. The Price-Jones curves (Fig. 1) and the photomicrographs of the blood smears (Figs. 2 and 3) illustrate the change in the distribution of erythrocyte sizes after removal of the ovarian tumour.

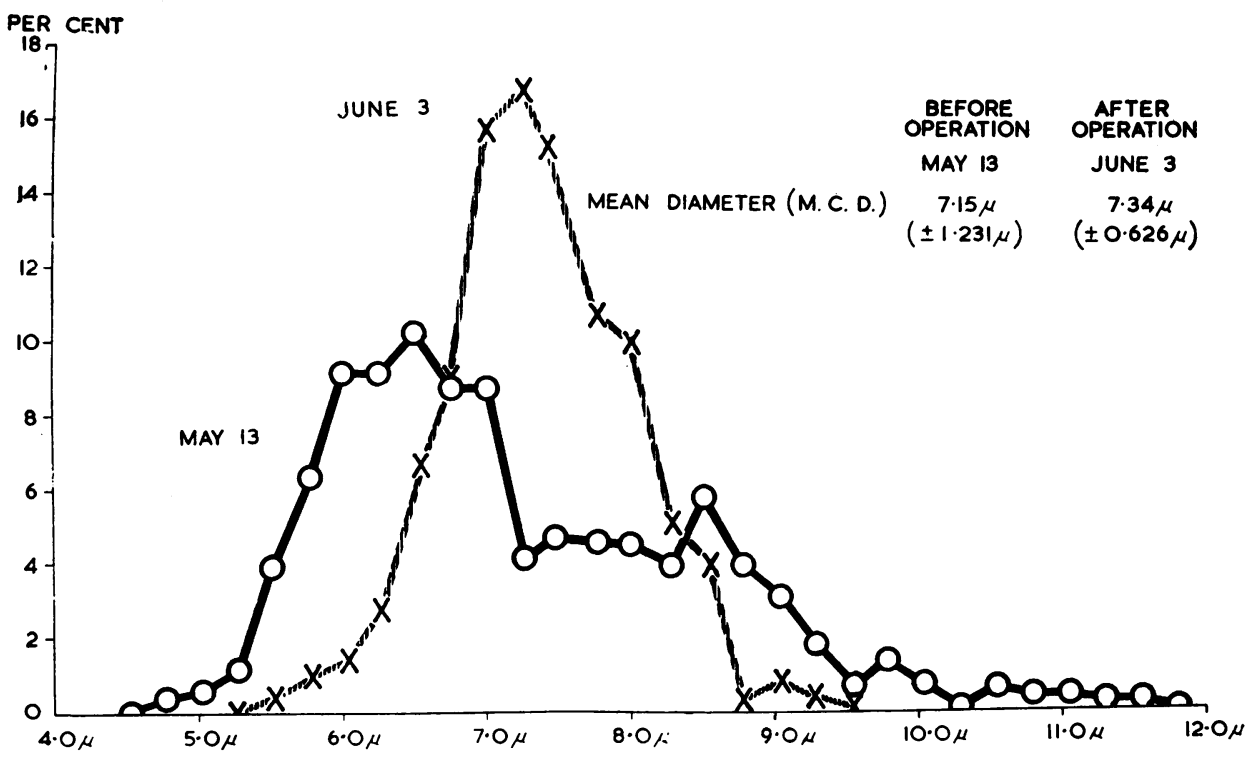

FIG. 1.-Frequency distribution of red cell diameters (Price-Jones curve). $\mathrm{O}-\mathrm{O}$ abnormally spread curve during period of active haemolysis with peaks representing microspherocytes and macroreticulocytes. $\times----\times$ Normal curve 10 days after operation.

Microspherocytes.-These were a prominent feature of every blood film made before operation and were, in fact, the first clue in the diagnosis of haemolytic anaemia. These abnormal cells disappeared completely from the blood film two days after operation.

Nucleated Red Cells.-Nucleated red cells were seen in every blood film before operation and in none afterwards. On two occasions in the pre-operative course of the disease, they numbered 5 per 100 white blood cells. They were all late (orthochromatic) normoblasts. 


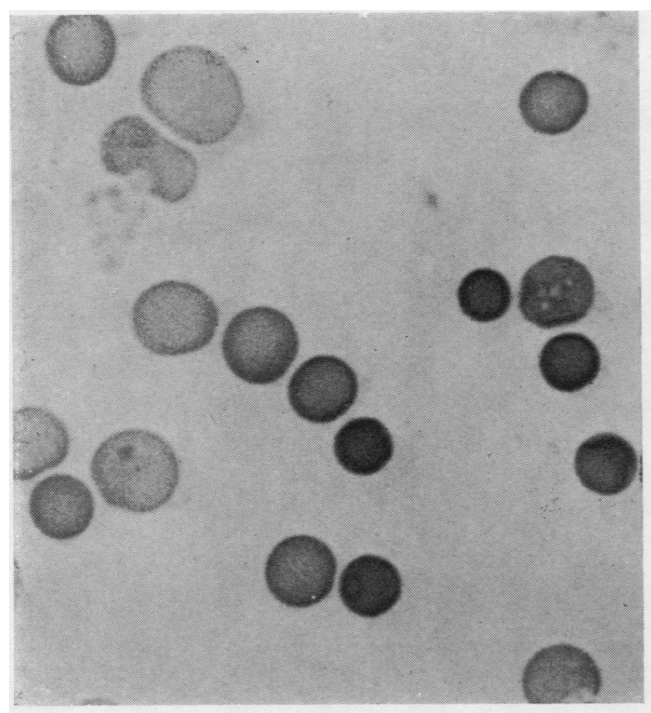

Fig. 2.-Blood film of May 13 showing microspherocytes and gross anisocytosis.

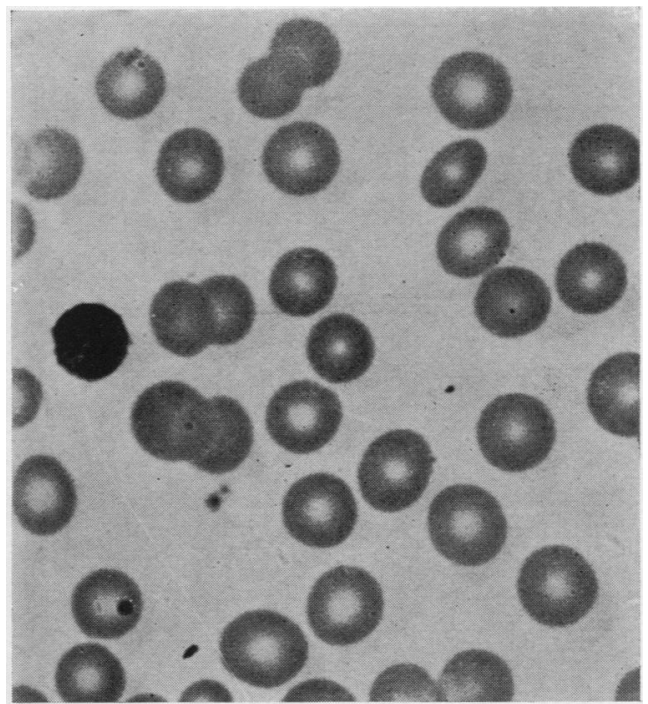

Fig. 3.-Blood film of June 3 showing normal red cells (a lymphocyte on left).

Reticulocytes.-The proportion varied between 33 and $47 \%$ of erythrocytes before operation, the highest count being made in the period of acute relapse. On the day after operation and after transfusion, reticulocytes were $10 \%$, and fell to the normal figure of $0.3 \%$ four weeks later.

Leucocytes.-The total white cell count varied from 21,800 to 10,000 per c.mm. before operation, and from 15,400 to 8,400 per c.mm. after operation. There was no important abnormality of the differential leucocyte percentages.

Fragility of Red Blood Cells.-A greatly increased fragility in saline dilutions was noted on admission, some haemolysis even being evident in $0.9 \%$ saline. A month after operation the fragility curve was virtually normal (Fig. 4), and three months later lay well within normal limits with $50 \%$ haemolysis at $0.35 \%$ saline.

Cold Agglutinins.-These were not demonstrated in tests performed on May 9 and May 11 using the technique of Stats and Wasserman (1943).

Circulating Haemolysins. - No circulating haemolysins could be demonstrated at $4^{\circ} \mathrm{C}$., $18^{\circ} \mathrm{C}$, and $37^{\circ} \mathrm{C}$. when the serum was tested against the patient's own washed corpuscles and the washed corpuscles of a healthy control subject of the same ABO group, with or without added guinea-pig complement.

The Donath-Landsteiner reaction for cold iso-haemolysins was negative.

The Race-Coombs test (developing test with anti-human-globulin rabbit serum) was negative on May 6.

Blood Groups.-Patient: Group O. Rhesus-positive. No atypical antibody. Patient's mother: Group A. Rhesus-positive.

The Kahn test was negative. 


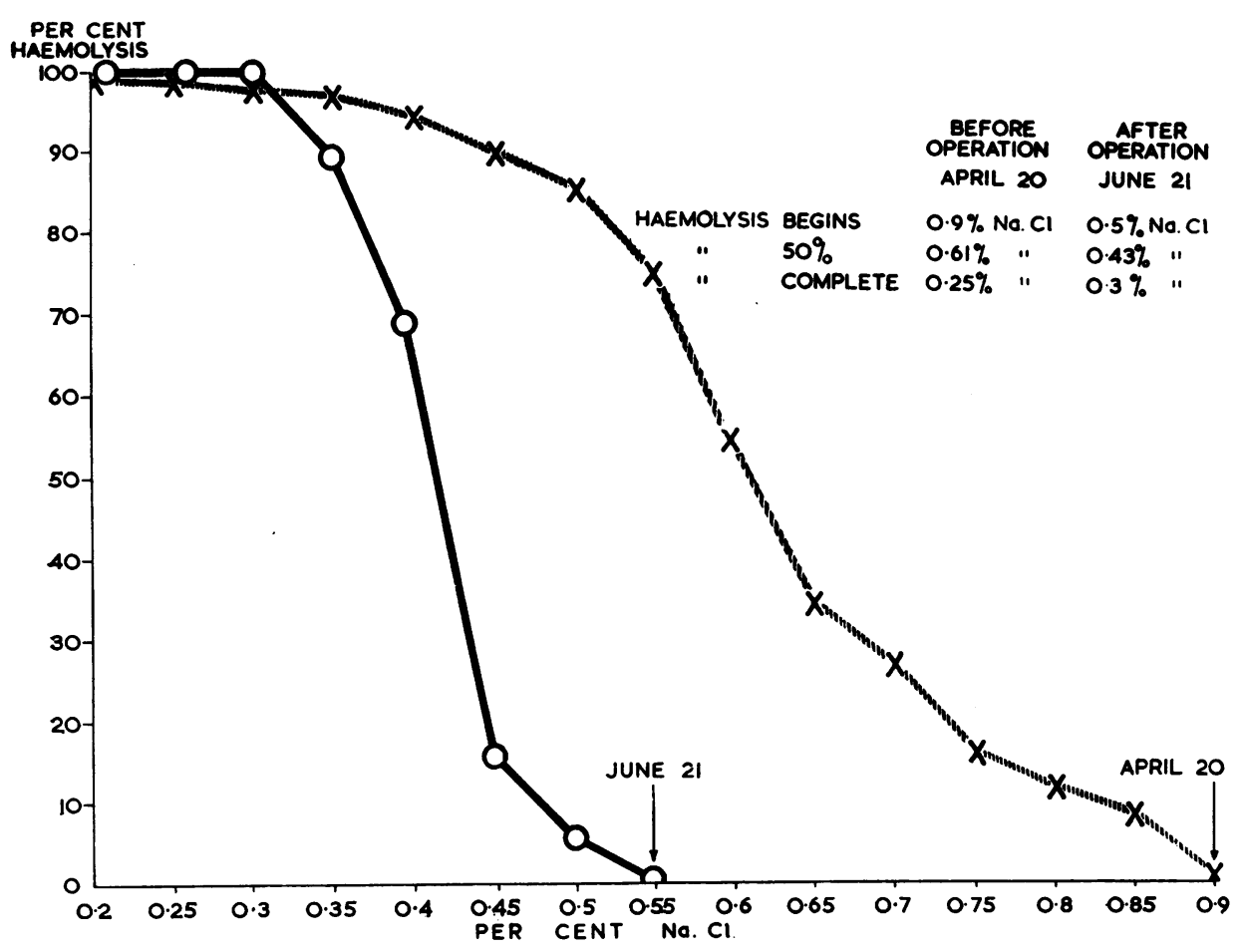

Fig. 4.-Erythrocyte fragility curves one month before and one month after removal of ovarian teratoma.

Faecal Urobilinogen.-This was estimated before and after operation.

\begin{tabular}{|c|c|c|c|c|c|c|c|c|}
\hline \multirow{2}{*}{ Before operation-May } & \multirow{3}{*}{$\begin{array}{r}8 \\
17 \\
18\end{array}$} & \multirow{2}{*}{$\begin{array}{l}\cdots \\
\ldots\end{array}$} & \multirow[b]{2}{*}{.. } & \multicolumn{5}{|c|}{$600 \mathrm{mg} . / 100 \mathrm{~g}$. of fresh faeces } \\
\hline & & & & 800 & ," & ,", & ," &, \\
\hline & & .. & . & 520 & ," & , & ," & ," \\
\hline \multirow{3}{*}{ After operation-June } & 19 & . & .. & 790 & ," & ," & ,", & ," \\
\hline & 9 & . & . & 89 & ", & , & , & ", \\
\hline & 10 & . & .. & 79 & ," & " & ," & $"$ \\
\hline
\end{tabular}

All the pre-operative values (determined by Maclagan's (1946) method : normal range 30-220 mg./100 g.) for faecal urobilinogen were greatly increased.

The test for faecal occult blood was negative.

Serum Bilirubin.-On April 21 the direct van den Bergh reaction was negative, and the indirect reaction was positive at $3.0 \mathrm{mg}$. bilirubin per $100 \mathrm{ml}$.

Serum Proteins.-On April 21 the total level was $6.5 \mathrm{~g} . / 100 \mathrm{ml}$. (albumin, 4.5 g./100 ml., globulin, 2.0 g./100 ml., A : G ratio, 2.25).

Sternal Marrow Puncture.-A puncture on May 16 gave the following results :

Total nucleated cells $=664,000$ per c.mm.

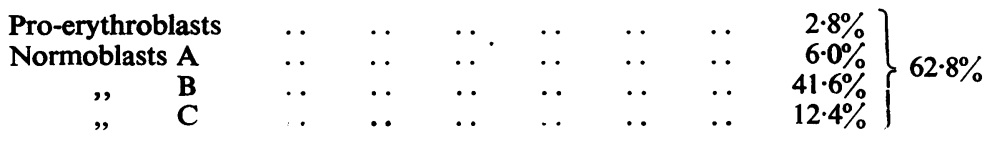


The results indicated a highly cellular bone marrow with a greatly exaggerated activity of red cell production, but no abnormality of other cellular elements except relatively decreased proportions.

\section{The Ovarian Tumour}

This rounded, smooth-surfaced tumour, measuring $7.5 \times 6 \times 4 \mathrm{~cm}$. in its main axes, weighed $100 \mathrm{~g}$. Its thickened pedicle had been clamped and contained a portion of ovarian tissue. Fluid contents were aspirated through a wide bore needle and replaced by fixative. The tumour was opened after fixation and after the tooth and calcified tissue had been located on the $x$-ray screen.

The sliced tumour (Fig. 5) was seen to be a unilocular cystic teratoma filled with coils of hair and thick sebaceous matter and enclosed by a tough, smooth, fibrous wall. At a point on this wall a little removed from the pedicle there lay an eminence of solid

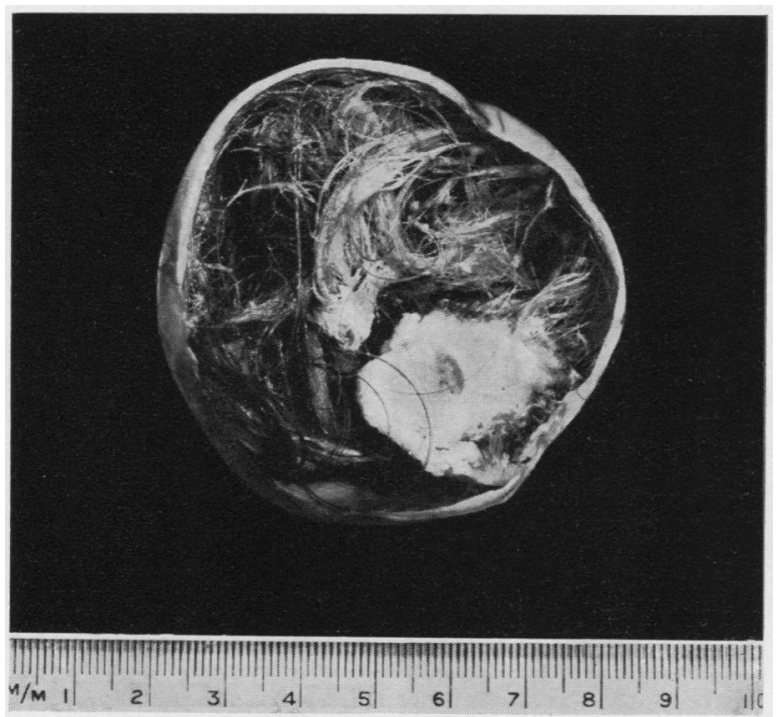

Fig. 5.-Unilocular cystic teratoma ("dermoid cyst") removed from right ovary on May 24.

tissue projecting $2 \mathrm{~cm}$. into the cyst cavity. This mass contained the follicles from which most of the hair arose, and also the tooth, some bone, and many other tissues only identified microscopically. The tooth was unerupted.

Histology.-The thinner parts of the wall were formed of laminated collagenous fibrous tissue covered externally by peritoneum and lined within by much attenuated stratified squamous epithelium, beneath which were found a few skin appendages. The pedicle comprised a part of normal ovary, separated from the tumour by a band of fibrous tissue continuous with that in other parts of the cyst wall, but bearing larger and more prominent blood vessels. Sections prepared at varying distances through the solid eminence in the tumour showed an intermingling of tissues representing all three germinal layers and demonstrated that this, like every other neoplastic "dermoid" cyst, was a teratoma of tridermal origin. The following tissues in particular were noted : skin and skin appendages, a tooth and dental papilla, primitive myxoid connective tissue, adipose tissue, various types of fibrous tissue, trabeculated and compact bone, cartilage, gastric and intestinal mucosa. No splenic tissue was seen. 
Cyst fluid, withdrawn before fixation, was turbid and opalescent. Centrifuging brought down a little amorphous deposit which contained no cells. The supernatant fluid remained milky. It contained large numbers of fat globules and smaller refractive lipoid particles but no identifiable cholesterol crystals. Serial dilutions of the supernatant fluid, from $1 / 5$ to $1 / 2560$, were made in saline and tested against washed human red cells of homologous group with and without added guinea-pig complement, but no haemolysis occurred in any tube of the test or of the controls at $18^{\circ}$ or at $37^{\circ} \mathrm{C}$.

\section{Discussion}

We have found only four earlier records, properly substantiated, of symptomatic haemolytic anaemia associated with ovarian tumours.

West-Watson and Young (1938) recorded such a case under the title of "Failed Splenectomy in Acholuric Jaundice." This was a woman of 44 . The anaemia was extremely severe, red cells being less than 1.0 million per c.mm., nucleated red cells 36,746 per c.mm., and leucocytes 13,353 per c.mm. The spleen, which weighed 500 g., was removed, but the patient became worse. She was maintained by transfusions. Laparotomy, four months later in an attempt to find an accessory spleen, revealed no abnormality other than an ovarian tumour which was removed faute de mieux. Unexpectedly, the haemolysis ceased immediately and signs of toxaemia disappeared. The patient recovered completely. The ovarian tumour was a " dermoid cyst" in which no splenic tissue was found histologically.

Watson (1939) described the case of a girl aged 19 with two years' history of jaundice. Haemoglobin was $32 \%$. The blood was moderately macrocytic, reticulocytes were $15 \%$, saline fragility was normal. Faecal urobilinogen was greatly increased. A large ovarian cyst, containing $800 \mathrm{ml}$. of fluid-altered blood, was removed. There was no improvement in the anaemia. Pyrexial and haemolytic reactions followed transfusions. Finally the spleen, weighing $440 \mathrm{~g}$., was removed. Another haemolytic crisis followed splenectomy, but thereafter the patient slowly recovered completely.

Singer and Dameshek (1941) reported a 47-year-old woman with severe anaemia, the blood showing spherocytosis, reticulocytosis, erythroblastosis, and increased saline fragility. Only temporary improvement followed splenectomy, but the patient was cured by the removal of a teratoma arising from the left ovary. This was a unilocular "dermoid" cyst $7 \mathrm{~cm}$. in diameter. No definite splenic tissue was seen microscopically.

Jones and Tillman (1945) observed a woman aged 35 with severe anaemia (5-7 g. $\mathrm{Hb} / 100 \mathrm{ml}$.), reticulocytes up to $20 \%$, and slightly increased saline fragility. Her blood, which was $\mathrm{Rh}$-negative, contained agglutinins to Group $\mathrm{O}$ Rh-positive cells and also to Group $\mathrm{O}$ and Group $\mathrm{A} \mathrm{Rh}$-negative cells. Auto-agglutinins were demonstrated, but cold agglutinins were not present. She also suffered from dermatomyositis, and had had attacks of intestinal obstruction. Obstructive peritoneal bands and a right ovarian cystic tumour were removed. The latter proved to be a pseudo-mucinous cystadenocarcinoma. The haemolytic anaemia appeared to have been relieved by this operation. There was a later acute intestinal obstruction.

Symptomatic haemolytic anaemia has been described in other morbid conditions. Carcinoma, sarcoma, leukaemia, and Hodgkin's disease are named by Watson, by Singer and Dameshek, and by Davis. Watson has also observed it in association with cirrhosis of the liver and with hyperthyroidism. Sarcoidosis and Gaucher's 
disease are mentioned by Singer and Motulsky (1949), and acute infections by nonhaemolytic micro-organisms by Singer and Dameshek. Fisher (1947) points to the frequency of increased haemolysis as a symptom in other blood diseases such as pernicious and related macrocytic anaemias, leuco-erythroblastic anaemia, and aplastic anaemia, but in these circumstances the criteria governing the definition of symptomatic haemolytic anaemia are not fulfilled.

The failure to demonstrate abnormal haemolysins, agglutinins, and atypical antibodies in our case in either the blood or the cyst contents is disappointing, since there is now much evidence to suggest that every variety of acquired haemolytic anaemia is due to some pathological haemolytic mechanism of this kind. Dameshek and Schwartz (1940) showed that spherocytosis is the morphological expression of an alteration in the structure of erythrocytes produced by various types of haemolytic substance, and microspherocytes were a prominent feature in the blood films of our patient. Loutit and Mollison (1946) demonstrated that red cells of patients with acquired acholuric jaundice on transfusion to normal recipients survive normally, whereas these same patients rapidly eliminated normal red cells transfused into them. They also showed that washed red cells of patients with acquired haemolytic jaundice were agglutinated by anti-human-serum rabbit serum, suggesting that these red cells had absorbed an immune antibody from their plasma. This latter observation was confirmed by Singer and Motulsky (1949), using anti-human-globulin rabbit serum as in the direct Race-Coombs test. The test was positive in seven cases of acquired haemolytic anaemia of unknown causation and in one case of symptomatic haemolytic anaemia associated with reticulo-sarcoma. It was negative in all except one gravely ill patient with haemolytic anaemia due to sulphonamide. Only one case of symptomatic haemolytic anaemia, that associated with reticulo-sarcoma, was so tested. In our patient the Race-Coombs test was negative, so we have no evidence to support, nor are we in a position to deny, the current theories of the mechanism of acquired haemolytic disease. One thing, however, is quite clear, that in such a case as ours the spleen does not play a dominant role. The haemolytic process must be conditioned by the presence of the tumour, and the conception of symptomatic haemolytic anaemia in these circumstances is fully justified.

There is a strong presumption that removal of the ovarian teratoma in this case cured the haemolytic anaemia, but this is not conclusively proved. Certain forms of acute haemolytic anaemia are arrested by blood transfusion. However, the relatively chronic course of the anaemia in this child, the absence of pyrexia at any time, the persistence of signs of haemolysis in the four days following the first transfusion, and the already known association of haemolytic anaemia with ovarian tumour are points which argue against transfusion being the effective therapy. West-Watson and Young specifically mention that transfusions in their patient failed to arrest the haemolytic process which, however, ceased immediately after removal of the ovarian teratoma. The possibility that our patient was, in fact, suffering from a crisis of familial acholuric jaundice can be dismissed because there was no earlier history to suggest the disease either in the patient or in her family ; after removal of the ovarian tumour red cell fragility returned completely to normal, and there were no further symptoms, in spite of the spleen being retained ; erythrocyte fragility tests, red and white cells and reticulocytes, and film appearances were all normal in the patient's mother, in her only sister, aged $7 \frac{1}{2}$, and in her only brother, aged 1 year. 


\section{Summary}

A girl, aged 4 years 9 months, suffered from severe haemolytic anaemia characterized by microspherocytosis, reticulocytosis, greatly increased erythrocyte fragility, and an excessive output of faecal urobilinogen.

The haemolytic process was completely arrested following the excision of a unilocular cystic teratoma of the right ovary. The spleen, which was of normal size, was not removed.

Neither circulating haemolysins nor atypical agglutinins were demonstrated.

We are grateful to Mr. A. J. C. Latchmore for his surgical co-operation, to Professor F. S. Fowweather for the biochemical estimations, to Dr. H. S. Baar for his advice on the case, and to our technical assistants.

\section{REFERENCES}

Dameshek, W., and Schwartz, S. O. (1940). Medicine, Baltimore, 19, 231.

Davis, L. J. (1944). Edinb. med. J., 51, 70.

Fisher, J. A. (1947). Quart. J. Med., 16, 245.

Jones, E., and Tillman, C. (1945). J. Amer. med. Ass., 128, 1225.

Loutit, J. F., and Mollison, P. L. (1946). J. Path. Bact., 58, 711.

Maclagan, N. F. (1946). Brit. J. exp. Path., 27, 190.

Singer, K., and Dameshek, W. (1941). Ann. intern. Med., 15, 544.

and Motulsky, A. G. (1949). J. Lab. clin. Med., 34, 768.

Stats, D., and Wasserman, L. R. (1943). Medicine, Baltimore, 22, 363.

Watson, C. J. (1939). Ann. intern. Med., 12, 1782.

West-Watson, W. N., and Young, C. J. (1938). Brit. med. J., 1, 1305. 